\title{
Assessment of Caries Spectrum of First Permanent Molars in 7- to 8-Year-Old School Children in Northern Saudi Arabia: A Cross-Sectional Study
}

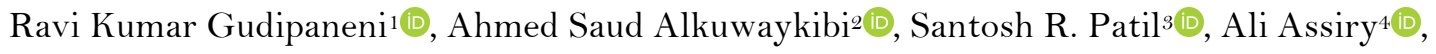 \\ Mohammad Khursheed Alam ${ }^{5}$, Sudhakar Vundavalli' ${ }^{(0)}$
}

\begin{abstract}
${ }^{1}$ Pediatric Dentistry Department, College of Dentistry, Jouf University, Sakaka, Saudi Arabia. ${ }^{2}$ College of Dentistry, Jouf University, Sakaka, Saudi Arabia.

${ }^{3}$ Oral Medicine and Radiology Department, College of Dentistry, Jouf University, Sakaka, Saudi Arabia.

${ }^{4}$ Pediatric Dentistry Department, College of Dentistry, Najran University, Sakaka, Saudi Arabia.

${ }^{5}$ Orthodontics Department, College of Dentistry, Jouf University, Sakaka, Saudi Arabia.

${ }^{6}$ Community Dentistry Department, College of Dentistry, Jouf University, Sakaka, Saudi Arabia.
\end{abstract}

Author to whom correspondence should be addressed: Ravi Kumar Gudipaneni, Assistant Professor, Pediatric Dentistry Department, College of Dentistry, Jouf University, Sakaka, Al Jouf, Saudi Arabia. Post box: 2014. Phone: +966540684272 . E-mail: drravimds@gmail.com.

Academic Editors: Alessandro Leite Cavalcanti and Wilton Wilney Nascimento Padilha

Received: O2 April 2019 / Accepted: 14 October 2019 / Published: 25 October 2019

How to cite this article: Gudipaneni RK, Alkuwaykibi AS, Patil SR, Assiry A, Alam MK, Vundavalli S. Assessment of caries spectrum of first permanent molars in 7- to 8-year-old school children in Northern Saudi Arabia: a cross-sectional study. Pesqui Bras Odontopediatria Clín Integr. 2020; 20:e4800. https://doi.org/10.1590/pboci.2020.005

\begin{abstract}
Objective: To estimate caries spectrum in first permanent molars (FPMs) of 7- to 8-year-old children in Saudi Arabia using Caries Assessment Spectrum and Treatment (CAST) index, and examine the correlation between distributions of CAST codes among contralateral and opposite arches. Material and Methods: A cross-sectional survey was conducted of 7- to 8-year-old Saudi school children in Sakaka, Aljouf, Saudi Arabia. A total of 385 children were examined. CAST codes were determined for FPMs, and their distribution was analyzed using Spearman's rank correlation coefficient. Statistical significance was set as $\mathrm{p}<0.05$. Intra-examiner reliability was determined using the unweighted kappa coefficient. Results: The results indicated most of the FPMs were scored as code 3 (enamel lesions) such as upper contralateral FPM $44.40 \%$ for right, $53.50 \%$ for left, respectively, and lower contralateral molars were $61.30 \%$ for right and $64.90 \%$ for left, respectively. It was also observed that upper FPMs had scored code o (sound teeth) more than that of lower FPMs. Serious morbidity (codes 6 and 7) and mortality (code 8) showed a low prevalence in FPMs. Strong correlations were observed between upper contralateral FPMs $(r=0.586)$ and lower contralateral FPMs $(\mathrm{r}=0.567, \mathrm{p}<0.001)$. Conclusion: A high prevalence of enamel caries lesions (code 3 ) was observed in FPMs; in addition, a strong correlation was present between upper contralateral FPMs and between lower contralateral FPMs.
\end{abstract}

Keywords: Dental Caries; Dentition, Permanent; Molar; Dental Care for Children. 


\section{Introduction}

Dental caries impacts the health and development of children. In recent years, the global distribution of dental caries has varied widely; in the past few decades an increase in the prevalence of dental caries has been observed in Saudi Arabia [1]. This change can be attributed to a change in the lifestyle of Saudis, which now involves increased consumption of sugary foods and carbonated drinks and a lack of awareness toward proper oral health maintenance [Q].

The first permanent molars (FPMs) have an important role in the development of occlusion since they are very prone to develop caries due to their anatomical structure and early eruption in the mouth. The quantification of dental caries in a population is the first step toward understanding the trends and characteristics of dental caries. Various indices have been used to measure dental caries. The decayed, missed, and filled teeth (DMFT) index [3], the most commonly used tool in epidemiological surveys, has failed to meet the current challenges. Therefore, in recent decades, the International Caries Detection and Assessment System (ICDAS) has been developed [4], which has the advantage of ability to distinguish the three stages of caries severity in the enamel; however, ICDAS requires complete drying of the tooth surface using dry air and double-checking, which leads to longer survey time and high cost [5].

The CAST index was developed in 2011[5] to measure the full spectrum of dental caries such as sound, fissure sealed and restored; dental caries in the enamel and dentin; advanced phases of untreated lesions involving the pulp and supporting tooth structures; and subsequent tooth loss, in order. The CAST index codes follow a hierarchical order in describing the severity of dental caries [6].

The advantage of CAST index is that it defines restored teeth as sound and healthy teeth, which is an epidemiologically replicates good healthy status [7]. The index disregards the need for drying the tooth surface; therefore, it is an easy system to implement at a community level [7]. Moreover, acceptance of CAST index has been increased globally and was recognized as a potentially valuable instrument for planning dental caries control programs for both high risk and mass approaches [8]. The CAST index has also been validated for its form and content [8].

This study was designed to estimate the caries spectrum in FPMs of 7- to 8-year-old children in Saudi Arabia, with the use of the CAST index, and determine the correlation between the distribution of CAST codes among contralateral and opposite arches of FPMs.

\section{Material and Methods}

Study Design and Sample

This cross-sectional survey was conducted in the Sakaka district in Aljouf province, a region situated in the northern part of Saudi Arabia, between August 2017 and March 2018.

The study sample comprised of primary school-going Saudi children of ages between 7 and 8 years old and utilized a random stratified cluster sampling to estimate the caries status of the FPMs. There are 38 public primary schools, with a total of 7437 children, in the Sakaka district of Aljouf province. The data about schools was attained from the Ministry of Education, KSA. The minimum required sample size was calculated as 384, based on a statistical significance of $5 \%$ and a confidence level of $95 \%$, and assuming the prevalence of caries in the FPMs to be $50 \%$. The sample size was adjusted to 420 with the assumption of $10 \%$ non-participation, incomplete data, ineligibility, etc. A total of 420 boys were clinically examined. These children were randomly selected using a stratified cluster method from 10 different public schools. 
The inclusion criterion was the eruption of all four FPM teeth. If any of the erupted FPMs was affected by hypoplasia or developmental abnormalities, the child was excluded from the study. Hence, 35 participants were excluded from the study, and 385 individuals were included in the final analysis.

\section{Data Collection}

Before the start of the main study, examiners were trained and calibrated under the supervision of a paediatric dentist; all dental examinations were conducted by two calibrated examiners. Dental examination was conducted on ten children each day in two sessions utilizing CAST index codes [5] shown in Table 1.

Table 1. Codes and Description of CAST index.

\begin{tabular}{|c|c|c|}
\hline Codes & Characteristic & Description \\
\hline 0 & Sound Tooth & No visible evidence of a carious lesion is present. \\
\hline 1 & Sealed & Pits and/ or fissures are at least partially sealed with a sealant material. \\
\hline 2 & Restored & A cavity has been restored with an (in) direct restorative material. \\
\hline 3 & Enamel & $\begin{array}{l}\text { Distinct visual change in enamel only. A clear caries discoloration is visible with or without } \\
\text { localized enamel breakdown. }\end{array}$ \\
\hline 4 & Dentine & $\begin{array}{l}\text { Internal caries related discoloration in dentine. The discolored dentine is visible through } \\
\text { enamel which may or may not exhibit a visible localized breakdown of enamel. }\end{array}$ \\
\hline 5 & Dentine & Distinct cavitation into dentin. The pulp chamber is intact. \\
\hline 6 & Pulp & $\begin{array}{l}\text { Involvement of pulp chamber. Distinct cavitation reaching the pulp chamber or only root } \\
\text { fragments is present. }\end{array}$ \\
\hline 7 & Abscess/Fistula & $\begin{array}{l}\text { A pus containing swelling or pus releasing sinus tract related to a tooth with pulpal } \\
\text { involvement. }\end{array}$ \\
\hline 8 & Lost & The tooth has been removed because of dental caries. \\
\hline 9 & Others & Does not correspond to any of the other categories. \\
\hline
\end{tabular}

The intra- and inter-examiner reproducibility was evaluated using the kappa statistics. For the interexaminer reliability, about $10 \%$ of the evaluated population was reexamined after three weeks. The CAST score of each FPM was documented on a form designed for use in the study. If the same tooth surface had two conditions, a higher score was recorded. For example, if there was a sealant in one pit and an enamel caries lesion in another, a score for enamel caries lesion was recorded. The highest possible code for each FPM was used for analysis.

School dental visits were made on predetermined dates. The examiners contacted the designated schools two weeks prior to the oral examination to dispense informed consent forms and self-administered questionnaires. The questionnaire collects the information on the child's age and gender, as well as demographic details, such as parental education and occupation. During the study, the oral examinations was conducted in the schools after gaining informed consent from the caregivers. Children who failed to provide consent were excluded from the study. Disposable examination kits and artificial light were used while a child sat on a portable chair. All the school children were asked to brush their teeth before the clinical examination. The dental caries status of FPMs was examined by a plane mouth mirror and a periodontal probe (WHO probe) with a $0.5-\mathrm{mm}$ ball end tip. The probe was also used to dislodge the dental plaque and food debris.

\section{Statistical Analysis}

The prevalence of each CAST code in FPMs was analyzed using SPSS version 21 (IBM Corp, Armonk, NY, USA). The correlation of the distribution of CAST codes between FPMs was evaluated using Spearman's rank correlation coefficient. The intra- and inter-examiner reliability was calculated using an unweighted Kappa coefficient. 


\section{Ethical Aspects}

Ethical clearance for the present study protocol was obtained from the Local Committee of Bioethics, Jouf University, KSA prior to beginning of the study (LCBE Approval No: 15-16-8/39) and written voluntary informed consent was obtained from the parents/caregivers of the selected school children after explaining the study objectives to the parent/caregiver. In addition, prior permission for this study was taken from the Ministry of Education. All procedures were in accordance with the Declarations of Helsinki.

\section{Results}

The assessment of intra-examiner reproducibility revealed a kappa of 0.97. Assessment of the interexaminer reproducibility of the two examiners revealed an unweighted kappa of 0.93 and 0.90 , respectively (examiners, RKG and ASA); this indicated excellent agreement between the examiners.

Table 2 shows the distribution of CAST codes in the evaluated FPM teeth. In the study population, 43.4\% of the upper right FPMs and 35.3\% of the upper left FPMs were scored as code 0 (sound teeth). Whereas, $8.10 \%$ of lower right FPMs and $10.40 \%$ of lower left FPMs were only scored code 0. Serious morbidity (codes 6 and 7) and mortality (code 8) were less prevalent in the FPMs; most of the FPM lesions were scored as code 3 (enamel caries lesions) (Figure 1). It was observed that none of the FPMs were restored with fissure sealants among the study population (code 1).

Table 2. Distribution of CAST codes in the first permanent molars.

\begin{tabular}{ccccccccccc}
\hline Tooth & $\mathbf{0}$ & $\mathbf{1}$ & $\mathbf{2}$ & $\mathbf{3}$ & $\mathbf{4}$ & $\mathbf{5}$ & $\mathbf{6}$ & $\mathbf{7}$ & $\mathbf{8}$ \\
\hline 16 & 167 & 0 & 3 & 171 & 11 & 11 & 22 & 0 & 0 \\
$\%$ & 43.4 & 0.0 & 0.8 & 44.4 & 2.9 & 2.9 & 5.7 & 0.0 & 0.0 \\
26 & 136 & 0 & 3 & 206 & 13 & 9 & 12 & 3 & 3 \\
$\%$ & 35.3 & 0.0 & 0.8 & 53.5 & 3.4 & 2.3 & 3.1 & 0.8 & 0.8 \\
36 & 40 & 0 & 14 & 250 & 13 & 26 & 17 & 16 & 9 \\
$\%$ & 10.4 & 0.0 & 3.6 & 64.9 & 3.4 & 6.8 & 4.4 & 4.2 & 2.3 \\
46 & 31 & 0 & 37 & 236 & 17 & 35 & 15 & 8 & 6 \\
$\%$ & 8.1 & 0.0 & 9.6 & 61.3 & 4.4 & 9.1 & 3.9 & 2.1 & 1.6
\end{tabular}

16: Upper Right First Permanent Molar; 26: Upper Left First Permanent Molar; 36: Lower Left First Permanent Molar; 46: Lower Right First Permanent Molar.

Table 3 shows the mean and standard deviation of CAST codes among FPMs. The results indicated that the mean values for the lower FPMs were higher than upper FPMs. It represents that lower FPMs were more frequently involved than the upper FPMs.

Table 3. Mean of CAST codes in the upper and lower first permanent molars.

\begin{tabular}{cc}
\hline Tooth & Mean \pm SD \\
\hline 16 & $1.94 \pm 1.86$ \\
26 & $2.17 \pm 1.80$ \\
36 & $3.23 \pm 1.69$ \\
46 & $3.16 \pm 1.50$ \\
\hline
\end{tabular}

Table 4 shows the results of Spearman's rank correlation among the FPMs. The results indicated a strong correlation exist between upper contralateral FPMs and lower contralateral FPMs (r=0.586, 0.567, $\mathrm{p}<0.001)$; whereas, a weak correlation between opposite arch FPMs $(\mathrm{r}=0.427,0.321, \mathrm{p}<0.001)$. 
Table 4. The correlation of CAST codes in molar teeth.

\begin{tabular}{ccc}
\hline Molar Teeth & $\mathbf{r}$ & p-value \\
\hline $16 / 26$ & $0.586^{* *}$ & $<0.001$ \\
$36 / 46$ & $0.567^{* *}$ & $<0.001$ \\
$16 / 36$ & $0.427^{* *}$ & $<0.001$ \\
$26 / 46$ & $0.321^{* *}$ & $<0.001$ \\
\hline Spearman's correlation coefficient; ** Correlation is significant at the 0.01 level.
\end{tabular}

\section{Discussion}

DMFT index identifies dental caries when the tooth surface has evidence of a cavity. It does not differentiate among various stages of the carious lesions. There has been a marked decline in the prevalence of cavitated lesions over the last decades in the developed countries, and the majority of the caries lesions are diagnosed at the initial stage [10,11]. On the other hand, some regions showed a high prevalence of advanced stages of dental caries with the involvement of the pulp and periapical tissue. Such information should be incorporated in the ideal caries screening systems $[6,11,12]$. However, CAST index includes the full spectrum of various stages of dental caries, such as sound surface (code 0), fissure sealants (code 1), restored (code 2), caries lesions in enamel and dentin (code 3, 4, 5), pulpal involvement (code 6), and periapical inflammation (code 7), and tooth loss due to caries (code 8) [13,14].

In our study, the percentage of children with caries-free (code 0 ) upper contralateral FPMs was greater than that of lower contralateral FPMs. The prevalence of sound FPMs was reported that 33\% among 9-year-old Saudi school children [15]. Whereas it has been reported that $89.7 \%$ of Indian school children had caries-free FPM teeth among 7- 8 years old [16]. The prevalence of FPM caries (diagnosed according to the WHO criteria) among 9-year-old Saudi schoolchildren has been reported as 67\% [15,17]. The high prevalence of dental caries in FPMs could be due to their anatomical structure, early eruption, and positioning in the dental arch [18].

The present study showed that none of the participants had FPMs that were restored with fissure sealants (code 1), indicative of the underutilization of fissure sealants. These findings were similar to those previously described [18]. In order to identify children with a high risk of caries, it has been suggested that screening for FPM teeth should start in 6-year-old children and continue to monitor for a certain period of time [19]. It has been recommended that fissure sealants are strongly recommended in high-risk children [1921]. The prevalence of fissure sealants in 7- to 8-year-old children in eastern European countries varies from $2.4 \%$ to $41.9 \%$ [22]. A study on the prevalence of caries and fissure sealants on the FPMs among 6- to 9-yearold Saudi girls showed that $64.6 \%$ of the children were caries-free and only $1.3 \%$ of the children had fissure sealant applied [17].

In the present study, the results indicated a high prevalence of FPMs with an enamel caries lesion (code 3). Moreover, the results indicated a very low proportion of FPMs affected by caries lesions reaching the pulp (code 6). It was observed that enamel lesions with ICDAS code 2 were the most prevalent lesions on occlusal surfaces of FPMs [23]. It has been reported that $67 \%$ of FPMs in schoolchildren in the UAE were scored CAST codes 4-7 [7]. A previous study in 7- to 8-year-old Polish children using the CAS index in primary and permanent molars revealed a higher number of cavitated lesions in the primary molars [13]. This is because, at the age of $7-8$ years, the exposure time for permanent teeth to the causative agents of dental caries is too short to induce the development of cavitated dentinal lesions. 
In this study, based on the mean CAST scores, the lower FPMs teeth had a high prevalence of caries than upper FPMs. In our study, the correlation between the caries status of the upper and lower FPMs was emphasized at the age of 7-8 years, because the anterior teeth are in the state of exchange. Hence, the exclusion of incisors and canines in this study provided a homogeneous sample of the population [13,16,23]. It was also observed that the Spearman rank correlation coefficient was statistically significant on all quadrants but showed the strongest correlation between the contralateral FPM teeth of the upper and lower arch. Similar results have been reported in 7- to 8-year-old Polish children [13].

Presently, ICDAS is the most advanced index for detecting early caries lesions by visual inspection. Although CAST was constructed based on the ICDAS, they differ in some aspects; for instance, CAST ignores the earliest enamel lesions, which are scored as code 1 in ICDAS. Epidemiological surveys using CAST or ICDAS may result in different rates of caries detection [24,25].

The CAST instrument is a comprehensive diagnostic tool for evaluating the whole caries spectrum in epidemiological surveys. So far, there is only a few studies have been conducted using the CAST index, and this has limited the comparison of our results. Further longitudinal studies from different geographic locations will be required to validate this index because it is a new instrument for caries assessment. However, results of studies using CAST scores can be compared to the results of ICDAS-based and conventional caries studies. The main advantage of CAST is the possibility of reporting the full spectrum of dental caries in a simple and clear manner [12].

A limitation of the CAST system is that it needs further validation of its reliability; however, due to the exclusion of the initial enamel lesions from the index, examiners would be less susceptible to making errors. Based on the results of the present study, there is a need for a prospective study to investigate whether poor conditions of deciduous molars affect the status of FPM teeth. Further studies in the similar age group in different regions of KSA are also advocated because the assessment of 7- to 8-year-old children will help in formulating guidelines for preventive measures; and will assist in the estimation of risk, and description of actual clinical presentation of preventable carious lesions to policy makers.

\section{Conclusion}

The CAST instrument provided a full range of stages in dental caries in the epidemiological survey. This study indicated a high prevalence of FPMs having an enamel caries lesion (code 3) and a very low prevalence of caries lesion involving the pulp (code 6). None of the participants had FPMs that were restored with fissure sealants (code 1), indicative of underutilization of fissure sealants. The strongest correlation was observed between contralateral FPM teeth of upper and lower arches.

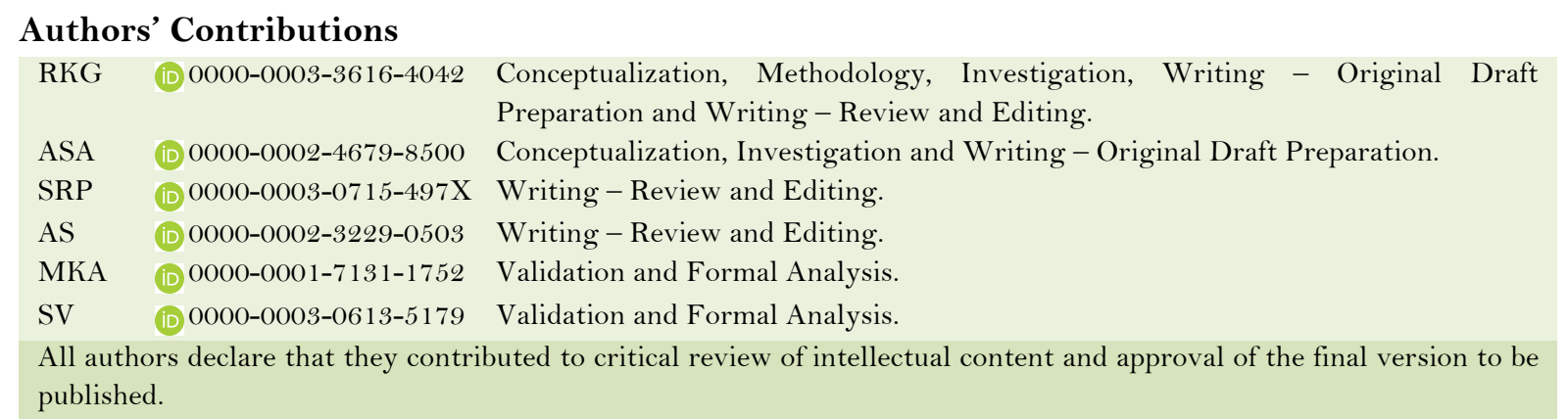




\section{Financial Support}

None.

\section{Conflict of Interest}

The authors declare no conflict of interests.

\section{Acknowledgement}

The authors gratefully acknowledge Dr. Bader K. Al Zarea, Dean, College of Dentistry, Jouf University, KSA, for his valuable support to complete the study.

\section{References}

[1] Al-Ansari AA. Prevalence, severity, and secular trends of dental caries among various Saudi populations: a literature review. Saudi J Med Med Sci 2014; 2(3):142-50. https://doi.org/10.4103/1658-631X.142496

[2] Farooqi FA, Khabeer A, Moheet IA, Khan SQ, Farooq I, ArRejaie AS. Prevalence of dental caries in primary and permanent teeth and its relation with tooth brushing habits among schoolchildren in Eastern Saudi Arabia. Saudi Med J 2015; 36(6):737-42. https://doi.org/10.15537/smj.2015.6.10888

[3] World Health Organization. Oral Health Surveys: Basic Methods. 4th. ed. Geneva: World Health Organization; 1997.

[4] Pitts NB, Ekstrand KR. International Caries Detection and Assessment System (ICDAS) and its International Caries Classification and Management System (ICCMS) - methods for staging of the caries process and enabling dentists to manage caries. Community Dent Oral Epidemiol 2013; 41(1):e41-52. https://doi.org/10.1111/cdoe.12025

[5] Frencken JE, de Souza AL, van der Sanden WJ, Bronkhorst EM, Leal SC. The caries assessment and treatment (CAST) instrument. Community Dent Oral Epidemiol 2013; 41(1):e71-7. https://doi.org/10.1111/cdoe.12027

[6] Frencken JE, de Amorim RG, Faber J, Leal SC. The Caries Assessment Spectrum and Treatment (CAST) index: rational and development. Int Dent J 2011; 61(3):117-23. https://doi.org/10.1111/j.1875-595X.2011.00022.x

[7] El Batawi H, Fakhruddin KS. Patterns of dental caries among school children assessed using Caries Assessment Spectrum and Treatment tool. Eur J Dent 2017; 11(2):168-73. https://doi.org/10.4103/ejd.ejd_120_17

[8] Leal SC, Ribeiro APD, Frencken JE. Caries Assessment Spectrum and Treatment (CAST): a novel epidemiological instrument. Caries Res 2017; 51(5):500-6. https://doi.org/10.1159/000479042

[9] Reich E. Trends in caries and periodontal health epidemiology in Europe. Int Dent J 2001; 51 (6 Suppl 1):392-8.

[10] Ismail A. Diagnostic levels in dental public health planning. Caries Res 2004; 38(3):199-203. https://doi.org/10.1159/000077755

[11] Monse B, Heinrich-Weltzien R, Benzian H, Holmgren C, van Palenstein Helderman W. PUFA - an index of clinical consequences of untreated dental caries. Community Dent Oral Epidemiol 2010; 38(1):77-82. https://doi.org/10.1111/j.1600-0528.2009.00514.x

[12] Fisher J, Glick M. A new model for caries classification and management: the FDI World Dental Federation caries matrix. J Am Dent Assoc 2012; 143(6):546-51. https://doi.org/10.14219/jada.archive.2012.0216

[13] Baginska J, Rodakowska E, Milewski R, Kierklo A. Dental caries in primary and permanent molars in 7-8-year-old schoolchildren evaluated with Caries Assessment Spectrum and Treatment (CAST) index. BMC Oral Health 2014; 14:74. https://doi.org/10.1186/1472-6831-14-74

[14] de Souza AL, van der Sanden WJ, Leal SC, Frencken JE. The Caries Assessment Spectrum and Treatment (CAST) index: face and content validation. Int Dent J 2012; 62(5):270-6. https://doi.org/10.1111/j.1875-595X.2012.00121.X

[15] Al-Samadani KH, Ahmad MS. Prevalence of first permanent molar caries in and its relationship to the dental knowledge of 9-12-year olds from jeddah, kingdom of saudi arabia. ISRN Dent 2012; 2012:391068. https://doi.org/10.5402/2012/391068

[16] Doneria D, Thakur S, Singhal P, Chauhan D, Jayam C, Uppal A. Comparative evaluation of caries status in primary and permanent molars in 7-8-year-old schoolchildren of shimla using caries assessment spectrum and treatment index. Contemp Clin Dent 2017; 8(1):128-33. https://doi.org/10.4103/ccd.ccd_886_16

[17] Alwayli HM, Alshiha SA, Alfraih YK, Hattan MA, Alamri AA, Aldossary MS. A survey of fissure sealants and dental caries prevalence in the first permanent molars among primary school girls in Riyadh, Saudi Arabia. Eur J Dent 2017; 11(4):455-460. https://doi.org/10.4103/ejd.ejd_189_17

[18] Noronha JC, Massara Mde L, Souki BQ, Nogueira AP. First permanent molar: first indicator of dental caries activity in initial mixed dentition. Braz Dent J 1999; 10(2):99-104.

[19] Berger S, Goddon I, Chen C-M, Senkel H, Hickel R, Stösser L, et al. Are pit and fissure sealants needed in children with a higher caries risk? Clin Oral Investig 2010; 14(5):613-20. https://doi.org/10.1007/s00784-009-0343-8

[20] Oulis CJ, Berdouses ED, Mamai-Homata E, Polychronopoulou A. Prevalence of sealants in relation to dental caries on the permanent molars of 12 and 15-year-old Greek adolescents. A national pathfinder survey. BMC Public Health 2011; 11:100. https://doi.org/10.1186/1471-2458-11-100 
[21] Masood M, Yusof N, Hassan MI, Jaafar N. Assessment of dental caries predictors in 6-year-old school children results from 5-year retrospective cohort study. BMC Public Health 2012; 12:989. https://doi.org/10.1186/1471-2458-12-989

[22] Runnel R, Honkala S, Honkala E, Olak J, Nommela R, Vahlberg T, et al. Caries experience in the permanent dentition among first- and second-grade schoolchildren in southeastern Estonia. Acta Odontol Scand 2013; 71(3-4):410-5. https://doi.org/10.3109/00016357.2012.690529

[23] Honkala E, Runnel R, Honkala S, Olak J, Vahlberg T, Saag M, et al. Measuring dental caries in the mixed dentition by ICDAS. Int J Dent 2011; 2011:150424. https://doi.org/10.1155/2011/150424

[24] Assaf AV, Meneghim MC, Zanin L, Pardi V, Pereira AC, Ambrosano GM. Influence of diagnostic adjuncts to the measurement of caries prevalence at different caries thresholds. Int Dent J 2003; 53(6):485-90. https://doi.org/10.1002/j.1875-595X.2003.tb00891.x

[25] Kassawara AB, Assaf AV, Meneghim Mde C, Pereira AC, Topping G, Levin K, et al. Comparison of epidemiological evaluations under different caries diagnostic thresholds. Oral Health Prev Dent 2007; 5(2):137-44. 